\title{
Habitat-suitability modelling to assess the effects of land-use changes on Dupont's lark Chersophilus duponti: A case study in the Layna Important Bird Area
}

\author{
Javier Seoane*, Jorge H. Justribó, Francisco García, Javier Retamar, \\ Cristina Rabadán, Juan C. Atienza
}

Sociedad Española de Ornitología (SEO/BirdLife), Unit of Environmental Policies, Melquiades Biencinto, 34, E-28053 Madrid, Spain

\section{A R T I C L E I N F O}

\section{Article history:}

Received 3 November 2004

Received in revised form

1 September 2005

Accepted 18 September 2005

Available online 8 November 2005

\section{Keywords:}

Predictive habitat modelling

SPA

Birds Directive

Shrub-steppe

CAP

\begin{abstract}
A B S T R A C T
Habitat-suitability modelling is being increasingly used as a tool for conservation biology. Although studies at large spatial scales are more appropriate for reserve design and management, there is a scarcity of published work on local, high-resolution applications of such models. In this work we develop high-resolution habitat models (1 ha) and study habitat preferences (focal points) of Dupont's lark Chersophilus duponti, an endangered shrubsteppe passerine, in the partially overlapping Special Protected Area for birds (SPA) and Important Bird Area (IBA) of "páramos de Layna" (NW Spain), to assess both the adequacy of the reserve's limits and the effect of land-use changes on the species' population size. Both analytical approaches show that the Dupont's lark favours flat areas characterized by small shrubs with bare ground, so that, for example, a conversion of dry crops to shrubs promoted by agri-environment schemes under CAP could increase the population size up to $80 \%$. Although the IBA and SPA are similar in size - as compelled by EU environmental policy - the latter shows rugged topography typically avoided by the species. We further discuss the possible conflict between EU environmental and agricultural policies on the conservation of this species and suggest it can be addressed with our study approach.
\end{abstract}

(c) 2005 Elsevier Ltd. All rights reserved.

\section{Introduction}

Conservation biologists and managers need a range of both classical analyses and specific modern tools to face the increasing threats to biodiversity (Caughley and Gunn, 1996; Austin, 2002). Among these tools, habitat-suitability modelling has recently emerged as a relevant technique to assess global impacts (for example, those due to climate change, Berry et al., 2002; Thuiller, 2003), to define wide conservation priorities (Margules and Austin, 1994), and to evaluate the completeness of regional nets of protected areas (Araújo and Williams, 2000). However, there are only a few published examples of high-resolution predictive habitat distribution models built to address local conservation problems (for example, Brotons et al., 2004), despite habitat models having frequently been mentioned as suitable for these particular needs as well (Guisan and Zimmermann, 2000; Manel et al., 2001).

Habitat models are static and data-based, as opposed to mechanistic or dynamic models of processes (Guisan and Zimmermann, 2000), and they have been criticized for lacking either an underlying theory or fine-grained data to 
explain the broad relationships observed between response and predictors (Conroy and Noon, 1996; Austin, 2002). Indeed most published habitat models favour their predictive over their explanatory ability, although we need both in most practical applications (Seoane et al., 2003). However, there is normally a trade-off between these two goals (MacNally, 2000). Explanatory fine-grained models built with direct predictors with immediate links with the species biology are difficult to generate for large areas, while coarse-grained models, whose interest rest more in their predictive ability, may be hard to understand (Bailey et al., 2002; Grand and Cushman, 2003; Bustamante and Seoane, 2004). A possible solution to this dilemma is to build models at several scales, with the high-resolution fine-grained models being used to understand basic species-habitat relationships, and the low-resolution coarse-grained models being used to draw predictive distribution cartography for the species under study. Such an approach would also address other scale effects on the perceived patterns of habitat selection (Riitters et al., 1997; Mazerolle and Villard, 1999; Orrock et al., 2000; Martínez et al., 2003).

The net of protected reserves in Spain includes just a small percentage of shrub-steppes, although this traditionally neglected habitat is very rare in Western Europe and harbours several species of European concern (Tucker and Evans, 1997; Morillo and Gómez-Campo, 2000) with worrying population trends (De Juana, 2004; Tella et al., 2005). One of the most endangered species is Dupont's lark Chersophilus duponti, whose unique European populations are dispersed across a number of fragmented areas in the Iberian Peninsula (Martí and Del Moral, 2003). Most of them occur within the net of Important Bird Areas (IBA) identified by the Spanish Ornithological Society (SEO/BirdLife) as those sites giving refuge to endangered species at a global or European level. This list of sites has been used for the last 10 years to designate Special Protection Areas for birds (SPA) in Spain under the enforcement of the Birds Directive (EC Birds Directive 79/409, Viada, 1998). However, only $42 \%\left(\sim 65,000 \mathrm{~km}^{2}\right)$ of the surface proposed as IBA has currently made it into the net of SPAs, and the actual limits of IBAs have not always been respected (own data, unpublished). This may be the case when landuse changes are foreseen in the near future (for example due to the development of infrastructure) and there is a temptation to define the final limits of the SPA by substituting the area deemed to be impacted with a supposedly suitable adjacent area.

Dupont's lark is an endangered poorly known terrestrial passerine that occupies a wide altitude range and favours open spaces covered with dispersed low shrubs, most of which would be marginal for agriculture and are currently used for grazing (Cramp, 1988; Garza et al., 2005). This lark is an early breeder territorial species, with males that sing loudly from either the ground or the top of short shrubs but are often difficult to spot. We lack accurate information about several basic aspects of the Dupont's lark biology, including microhabitat selection, but some studies have shown that their territories may be relatively large and highly clumped, which in addition to their escape behaviour (birds doing long runs when approached have been reported) make this species difficult to quantify (Garza et al., 2003; Tella et al., 2005).
Land-use changes on the areas the species occupies, driven by changing agricultural practice and the development of infrastructure, have been identified as major threats to its populations (Garza et al., 2005; Tella et al., 2005). A further concern is whether Common Agriculture Policy accompanying measures could be detrimental for the species. The Rural Development forms the "second pillar" of the CAP since the agenda 2000 reform of the EU agricultural policies, and environmental preservation is one of its main objectives (European-Communities, 2003). Among the four CAP accompanying measures that have been designed to that aim, two may have profound implications in landscape change: the agri-environmental measures and the afforestation of agricultural fields. However, the actual implementation of these generic environmental-friendly regulations may disregard local conservation needs in favour of their long-term objectives. Such is the case of the afforestation of marginal agricultural lands in valuable steppe habitats (Suárez et al., 1997; Franco and Sutherland, 2004). On the contrary, other measures, particularly those related to extensification of agrarian production and to exploitation systems of high environmental value, may benefit the species by promoting the conservation of a suitable landscape.

In this work we aim to show that a multiscale modelling strategy can aid in identifying effective measures for the management of endangered species through the identification and ranking of suitable areas for them. Taking the Layna shrub-steppes as a case study, we analyze habitat preferences of Dupont's lark at two scales and apply the results to address local - but generalizable - conservation issues for the species. First, we study lark's microhabitat preferences based on focal points, as compared to random points. Second, we build a habitat model of Dupont's lark distribution to develop a predictive map for the area of study (a pair of reserves comprising $\sim 42 \mathrm{~km}^{2}$ ). Finally, we show the usefulness of this multiscale approach by applying the models as a tool to assess: (i) the local population size of Dupont's lark, (ii) the adequacy of the design of the reserve that includes the area of study, and (iii) the effects of several likely land-use changes, following changing agricultural practices, on the number of breeding larks.

\section{Study area}

Our case study area $\left(\sim 45 \mathrm{~km}^{2}\right)$ includes the partially overlapping Special Protected Area (SPA) and Important Bird Area

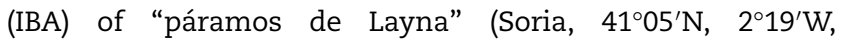
1200 m.s.n.m., see Fig. 1), that maintains one of the larger breeding populations of Dupont's lark, estimated between 250 and 500 pairs (Viada, 1998, p.190). Sixteen other IBAs have been proposed in Spain due to the presence of Dupont's larks. The study area is a grazed high plateau with a predominantly flat rocky topography that alternates with slightly undulating relief; both its northern and southeastern borders are limited by deeper valleys. The vegetation, a shrub secondary steppe (Tucker and Evans, 1997), comprises a gradient of closed to sparse thorny small shrub formations (dominated by Genista pumila and G. scorpius, $<40 \mathrm{~cm}$ in height) mixed with cereal dry crops, lavender (Lavandula sp.) cultures, and dry grasslands with dwarf shrub (mainly thyme, Thymus spp., 


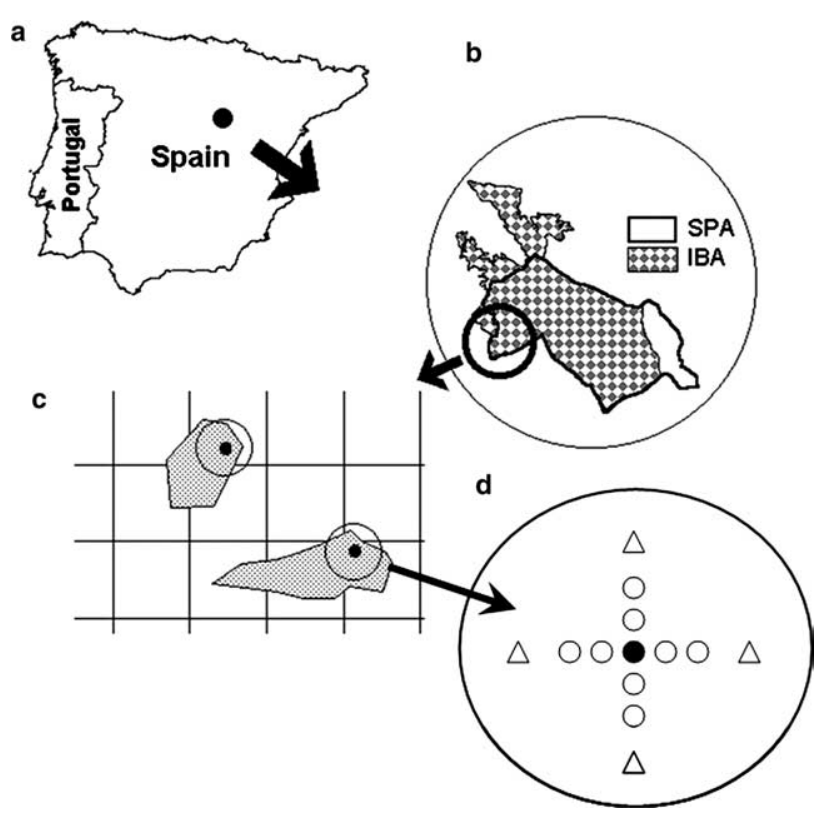

Fig. 1 - Study area. (a) Located on the northeast of Spain, (b) the Important Bird Area and Special Protection Area for birds of Layna (c) were divided into a grid of $100 \times 100 \mathrm{~m}$ (1 ha) squares to generate a vegetation map and to sample Dupont's Lark, Chersophilus duponti. Habitat models related the occurrence of larks in 1-ha squares to vegetation structure and topography, while the microhabitat analyses compared focal points where lark were detected to random sites. (d) Predictive variables (see Table 2) were measured in circles of $25 \mathrm{~m}$ in radius centred in sampling points (filled circle), at 6 and $8 \mathrm{~m}$ (vegetation, open circles) and $15 \mathrm{~m}$ (slope, triangles) in the cardinal directions.

$<20 \mathrm{~cm}$ in height). Some dispersed individuals of higher spiny shrubs (Rosa spp.) or saplings (both young or grazed Quercus spp. and Juniperus thurifera) can also be found.

The limits of the IBA and SPA do not match exactly (Fig. 1). The extent of the former covers $37.56 \mathrm{~km}^{2}$ and includes two narrow plains north of a recent high-speed train railway $\left(10.31 \mathrm{~km}^{2}\right)$, while the latter extents southward of the railway and includes an adjacent steep valley covered by similar shrub-steppe vegetation $\left(31.69 \mathrm{~km}^{2}\right)$.

\section{Methods}

\subsection{Microhabitat preferences}

Microhabitat preferences were studied comparing sites used by larks in the reproductive season to available sites. We georeferenced birds located while sampling transects of $100 \times 100 \mathrm{~m}$ squares ( $1 \mathrm{ha}$ ) that covered $66 \%$ of the study area (see below for sampling design and layout) with the aid of a GPS receptor (approx. error $<5 \mathrm{~m}$ ). The observer approached the shrub where a bird was seen singing and marked its position (with aural contacts the observer tried to determine the position of birds by approaching them from several directions). We then registered microhabitat features in a sample of 57 (year 2001) and 33 (year 2004) focal points (hereafter "lark sites") where birds were detected and a complementary sample of 57 (2001) and 181 (2004) randomly selected points (Larsen and Bock, 1986).

We estimated the percentage cover of grass, cereal cultures, bare ground, rocky surface and the predominant chamaephytes (Genista pumila, thyme and lavender) in circles of $25 \mathrm{~m}$ in radius centred in sampling points, as well as both the maximum and mean vegetation height, and the ruggedness of the terrain. Maximum vegetation height was measured as the height of the tallest shrub in the 25-metre radius circle. Mean vegetation height was estimated by averaging the maximum heights measured in eight points located at 6 and $8 \mathrm{~m}$ from sampling points and in the directions $\mathrm{N}, \mathrm{S}$, E, W (Fig. 1). Ruggedness of terrain was estimated as the standard deviation of slopes (in percentage) measured with a clinometer (SILVA CM 360, 1\% precision) at four points $15 \mathrm{~m}$ away from the centre of the circles.

We first assessed microhabitat preferences comparing lark sites and random sites with univariate Wilcoxon rank sum tests. Second, we carried out a Principal Component Analysis to have a multivariate summary of lark habitat preferences and to visually assess the range of variability among lark and random sites. Variables were normalized and standardized (mean $=0$, standard deviation $=1$ ) to account for differences in the scale of measure and the components rotated (varimax method) to ease their interpretation (Venables and Ripley, 1999, pp. 330-332).

\subsection{Habitat models}

We built habitat models to relate the occurrence of Dupont's lark with a set of potentially explanatory variables describing vegetation and topography for the whole area of study. In order to do that we first had to generate our own fine-grained vegetation map because previous thematic cartography for the study area was too coarse. We first divided the area of study in a grid of $100 \times 100$-metre spatial resolution, excluding from further consideration those squares with less than $50 \%$ of their surface within the SPA or IBA limits. We surveyed each hectare to register the percentage of its surface covered by (1) natural dry grasslands, (2) dry cereal cultures, open dwarf shrubs formations of (3) thyme and (4) lavender, (5) open Genista shrubs (sparse low rounded individuals interspersed with other chamaephytes, with $>50 \%$ of bare ground), (6) dense Genista pumila shrubs, (7) tree and (8) rock cover. We further calculated (9) slopes for the 1-ha squares through a Digital Elevation Model with mean square error $<3 \mathrm{~m}$ obtained from 1:25.000 topographic maps (MDT25) provided by the National Geographic Institute, with GIS software (Eastman, 1999).

We surveyed Dupont's lark occurrence in a sample of 2475 $100 \times 100 \mathrm{~m}$ squares that covered the whole variability in the main vegetation formations. The squares were visited between the 21st and 27th of April, 2001 during the first three hours after sunrise by a procedure close to the mapping method (Bibby et al., 2000). We walked slowly $(\sim 2.5 \mathrm{~km} / \mathrm{h})$ along curved transects designed to have a maximum separation of $300 \mathrm{~m}$. Thus, we were at most $150 \mathrm{~m}$ away from every point in the field, which is within the detection distance for a loud singer like our study species (Cramp, 1988). When we 
detected a bird we marked its position to identify the corresponding 1-ha square. To further evaluate the statistical models with independent data we made complementary censuses in 2004 (May and June, in this year the winter was particularly cold and the birds bred later than usually). Arranged along six irregular transects, 350 1-ha squares were visited between 06:15 and 09:30, recording the presence of larks within them. The transect layout attempted to cover the full range of predicted probabilities of a preliminary habitat model.

We built Generalized Linear Models to find habitat associations and to generate a predictive map of Dupont's lark distribution for the area of study. We modelled the occurrence (squares with recorded presence vs available squares) of birds in 1-ha squares with the vegetation cover percentages and slope as potential explanatory variables (variables 1-9 above), using logit link and binomial errors. Due to the widely different sample sizes for presences ( $n=53$ 1-ha squares) and absences ( $n=4200$, the whole area of study) we decided to use a resampling scheme. We choose 53 empty squares randomly out of the 4200 and we use this data to build a model together with the 53 squares with larks. We repeat the process 200 times. Potential explanatory variables with low variability were dichotomized (0: absence, 1: presence). We used an automated procedure to build the models by first fitting a maximal model that included potential predictors as linear terms, then trying to substitute linear terms of continuous predictors by second-order polynomials and finally testing second-order interactions among the remaining predictors. Calculations were performed with custom-made Splus 2000 code (MathSoft, 1999).

Final predictions for the 1-ha squares (probability of lark's presence) were the mean of the 200 minimum adequate final models, weighted by the inverse of models AIC (Akaike's Information Criterion), that is the lower the value, the higher the weight we gave to the predictions (the AIC trades off model fit and model complexity according to the formula: $-2 *$ Log-likelihood $+2 *$ number of parameters in the model). These averaged predictions were evaluated with an independent data set consisting in the 350 squares sampled in 2004. The accuracy of the predictive map was estimated with this new data set by calculating both the correct classification rate (CCR, transforming probability values from the model into binary values with a 0.5 threshold) and the AUC (a threshold-independent measure, Manel et al., 2001).

Last, we assessed the spatial structure in model residuals to look for an autocorrelation pattern suggesting that a relevant predictive variable is missing from the models. For example, we did not include variables that take into account interactions (such as conspecific attraction or territory competition). If these processes are relatively more important than habitat preferences in determining Dupont's Lark pattern of occupancy at our study resolution then our models will be weak. We assessed the existence of spatial structure in the residuals with Mantel tests, which are a permutation procedure to calculate the correlation between two data matrices, typically one describing the geography and the other one a variable whose spatial structure is being tested (Legendre and Fortin, 1989; Legendre, 1993). We applied Mantel tests to compare the matrix of residual distances (maximum absolute difference between each pair of residuals) with the corresponding one of geographic (Euclidean) distances. We also built 200 Mantel correlograms (one for each resampling model) to show the Mantel correlation among squares $100-200 \mathrm{~m}$ apart, then among squares $200-300 \mathrm{~m}$ apart, then two more $100-\mathrm{m}$ intervals until $500 \mathrm{~m}$ and from there on 20 intervals of $400 \mathrm{~m}(500-900,900-1300, \ldots, 8100-$ maximum distance).

\subsection{Assessment of population change}

We finally used the models to assess the effects of different land-use change scenarios on Dupont's lark population size. The first scenarios reproduce the likely effect of abandonment measures applied to current agricultural land. Following a common pattern in the serial evolution of abandoned land in the Mediterranean (Tucker and Dixon, 1997), the vegetation cover would change first to one mainly composed of dwarf shrubs (thymes) and afterwards to one composed of small thorny shrubs (Genista spp). We simulated the corresponding scenarios by changing the vegetation cover from dry cereal crops to either thyme (scenario 1) or Genista shrubs (scenario 2) in the thematic cartography we had previously developed. Afterwards, we used the models to predict on these scenarios and get new estimates of population size as the sum of the probabilities (and their standard errors). A third scenario was aimed to reproduce afforestation of culture land. In this case we changed dry crops cover to presence of tree cover (a dichotomous variable) and used the models to predict on the transformed thematic cartography.

Model predictions rarely have a 1:1 correspondence with observations recorded in other spatial or temporal instances different than the one in which the models were built (Ertsen et al., 1998; Whittingham et al., 2003). We studied this relationship with calibration graphs, plotting the proportion of evaluation 1-ha squares with presence of Dupont's lark within each of ten predicted probability classes against the observed occurrence in each class (see Pearce and Ferrier, 2000 for a detailed account of model calibration). A logistic regression fitted throughout the points describes the relationship between observations and predictions, thus allowing us to make a sensible conversion of predicted probabilities of occurrence into predicted numbers of pairs. Actual number of pairs within a given area was estimated by summing the predicted number of pairs in this area (we used non-parametric bootstrap on the models' predictions to obtain 95\% confidence intervals). Estimates of lark population sizes and changes following land-use modifications were corrected in this way.

\section{Results}

\subsection{Microhabitat preferences}

Lark sites were consistently characterized by a large cover of Genista shrubs (average of 39.6\%), no or very low cover of cereal $(<3 \%)$ and a terrain significantly more even than random sites (Table 1). Larks were only detected in sites with slopes lower than $9.5 \%\left(4.3^{\circ}\right)$. Maximum slopes (absolute values) were significantly lower for lark sites (lark sites: $4.6 \pm[\mathrm{SE}]$ 0.09 , random sites: $7.5 \pm 0.01, Z=-3.98, p=0.0001$ ). Also, there 
Table 1 - Mean values (and standard errors) of microhabitat variables measured in lark and random sites in 2001 and 2004

\begin{tabular}{|c|c|c|c|c|}
\hline \multirow[t]{2}{*}{ Variable } & \multicolumn{2}{|c|}{2001} & \multicolumn{2}{|c|}{2004} \\
\hline & $\begin{array}{c}\text { Lark sites } \\
\quad n=57\end{array}$ & $\begin{array}{c}\text { Random sites } \\
n=57\end{array}$ & $\begin{array}{l}\text { Lark sites } \\
\quad n=33\end{array}$ & $\begin{array}{c}\text { Random sites } \\
n=181\end{array}$ \\
\hline Dry grassland & $\begin{array}{l}15.4 \\
(3.12)\end{array}$ & $\begin{array}{l}25.2 \\
(3.78)\end{array}$ & $\begin{array}{l}15.8 \\
(1.89)\end{array}$ & $\begin{array}{l}37.3 \\
(1.95)\end{array}$ \\
\hline Dry cereal cultures & $\begin{array}{l}0 \\
(0.00)\end{array}$ & $\begin{array}{l}6.3 \\
(2.45)\end{array}$ & $\begin{array}{l}0 \\
(0.00)\end{array}$ & $\begin{array}{l}6.2 \\
(1.44)\end{array}$ \\
\hline Bare ground & $\begin{array}{l}25.7 \\
(2.44)\end{array}$ & $\begin{array}{l}24.5 \\
(3.24)\end{array}$ & $\begin{array}{l}18.5 \\
(1.79)\end{array}$ & $\begin{array}{l}15.0 \\
(1.30)\end{array}$ \\
\hline Rocky surface & $\begin{array}{l}10.1 \\
(0.88)\end{array}$ & $\begin{array}{l}9.7 \\
(1.51)\end{array}$ & $\begin{array}{l}2.3 \\
(0.44)\end{array}$ & $\begin{array}{l}6.3 \\
(0.59)\end{array}$ \\
\hline Genista & $\begin{array}{l}43.9 \\
(3.20)\end{array}$ & $\begin{array}{l}2.62 \\
(3.22)\end{array}$ & $\begin{array}{l}32.1 \\
(2.56)\end{array}$ & $\begin{array}{l}14.8 \\
(0.96)\end{array}$ \\
\hline Thyme & $\begin{array}{l}17.5 \\
(2.06)\end{array}$ & $\begin{array}{l}17.2 \\
(2.28)\end{array}$ & $\begin{array}{l}30.6 \\
(3.57)\end{array}$ & $\begin{array}{l}15.3 \\
(1.13)\end{array}$ \\
\hline Lavender & $\begin{array}{l}1.2 \\
(1.23)\end{array}$ & $\begin{array}{l}2.9 \\
(0.88)\end{array}$ & $\begin{array}{l}0.9 \\
(0.46)\end{array}$ & $\begin{array}{l}3.4 \\
(0.57)\end{array}$ \\
\hline Maximum vegetation height & $\begin{array}{l}84.8 \\
(7.81)\end{array}$ & $\begin{array}{l}109.0 \\
(14.99)\end{array}$ & $\begin{array}{l}45.9 \\
(5.83)\end{array}$ & $\begin{array}{l}154.3 \\
(13.20)\end{array}$ \\
\hline Mean vegetation height & $\begin{array}{l}17.6 \\
(0.95)\end{array}$ & $\begin{array}{l}17.1 \\
(1.24)\end{array}$ & $\begin{array}{l}17.4 \\
(0.41)\end{array}$ & $\begin{array}{l}22.5 \\
(2.57)\end{array}$ \\
\hline Ruggedness & $\begin{array}{l}3.2 \\
(0.26)\end{array}$ & $\begin{array}{l}6.4 \\
(0.75)\end{array}$ & $\begin{array}{l}3.1 \\
(0.30)\end{array}$ & $\begin{array}{l}5.0 \\
(0.35)\end{array}$ \\
\hline
\end{tabular}

Values are estimated percentage cover except for heights (in $\mathrm{cm}$ ) and ruggedness (the variance of four measures of slope in percentage). Bold font shows significant differences between sites (after Wilcoxon rank sum test with sequential Bonferroni correction, Rice, 1989).

is a tendency for lark sites to have more bare ground and cover of dwarf thyme shrubs, and for random sites to show a rockier surface and a larger cover of grasslands with higher maximum vegetation heights (normally due to sparse saplings and tall shrubs, see Table 1). There is a hint of interannual differences in microhabitat variables (e.g., a higher percentage of thyme and dry grasslands were recorded in 2004) to be attributed to a particularly cold and wet winterearly spring in 2004, which promoted vegetation growth and, in particular, grassland growth.

Three main principal components, explaining $51 \%$ of total variance of data, were identified. The first one accounts for $22 \%$ of data variability and describes a gradient of vegetation height, with correlation coefficients for bare ground, dry grassland, and maximum and mean vegetation height being $0.80,-0.73,-0.65$ and -0.63 respectively. The second axis explains $16 \%$ of predictors variability and distinguishes between natural vegetation and dry cereal crops (coefficients for cereal cultures, and percentage cover of thyme and Genista are 0.80 , -0.59 and -0.56 respectively). The third one accounts for an additional $12 \%$ of variability to identify rugged areas (coefficient for ruggedness is 0.75 ), and to further divide the natural vegetation between denser and taller Genista shrubs (-0.45) and lesser thyme shrubs (0.27) and grasslands ( -0.29 for mean vegetation height). In both the 2001 and 2004 data, lark sites occupy a tight region of the plane formed by the two first principal components, as opposed to a greater variability of random sites (Fig. 2a). However, both types of sites were similarly spread along the third component, although lark sites tend to cluster on the negative side (with more even terrain and larger cover of Genista scrub, Fig. 2b).

\subsection{Habitat models}

We built 200 habitat-models better than null models with fair discrimination abilities (mean CCR \pm standard deviation = $0.61 \pm 0.007 ;$ AUC $=0.66 \pm 0.004$ ) and generated a predictive map of Dupont's lark distribution by assigning to each 1-ha square its corresponding AIC-weighted average prediction (Fig. 3). Habitat-models correlated fairly well with microhabitat preferences, as shown by the fact that $84 \%$ of models included the percentage of Genista shrubs as a predictor with positive sign, while $61 \%$ included the percentage of grass and $12 \%$ the presence of dry cereal crops as predictors with negative sign (Table 2). Similarly, 73\% of models included slope with a negative sign, which agrees with not having observed larks on 1-ha squares with slopes steeper than $5.1 \%$.

Mantel tests among geographic distances and residual distances gave significant correlations ( $R$ within $[0.07,0.14])$ suggesting that there is some spatial structure in the residuals. Mantel correlograms exhibited a consistent pattern of negative correlation (increasing to zero) among neighbouring squares until distance $400 \mathrm{~m}$, but slight (between -0.04 and 0.00 ) and far away from significance, and an increasing correlation that normally reached significance between 6000 and $7000 \mathrm{~m}$ (but, nonetheless, being slight: the correlation ranges from 0.03 to 0.04 , Fig. 4). Long-distance autocorrelation is just due to the elongated shape of the reserve and the fact that peripheral areas are worse that two central nucleus (Fig. 3), thus the modelling procedure does not seem to be impaired by spatial autocorrelation and we will not further discuss this issue. 


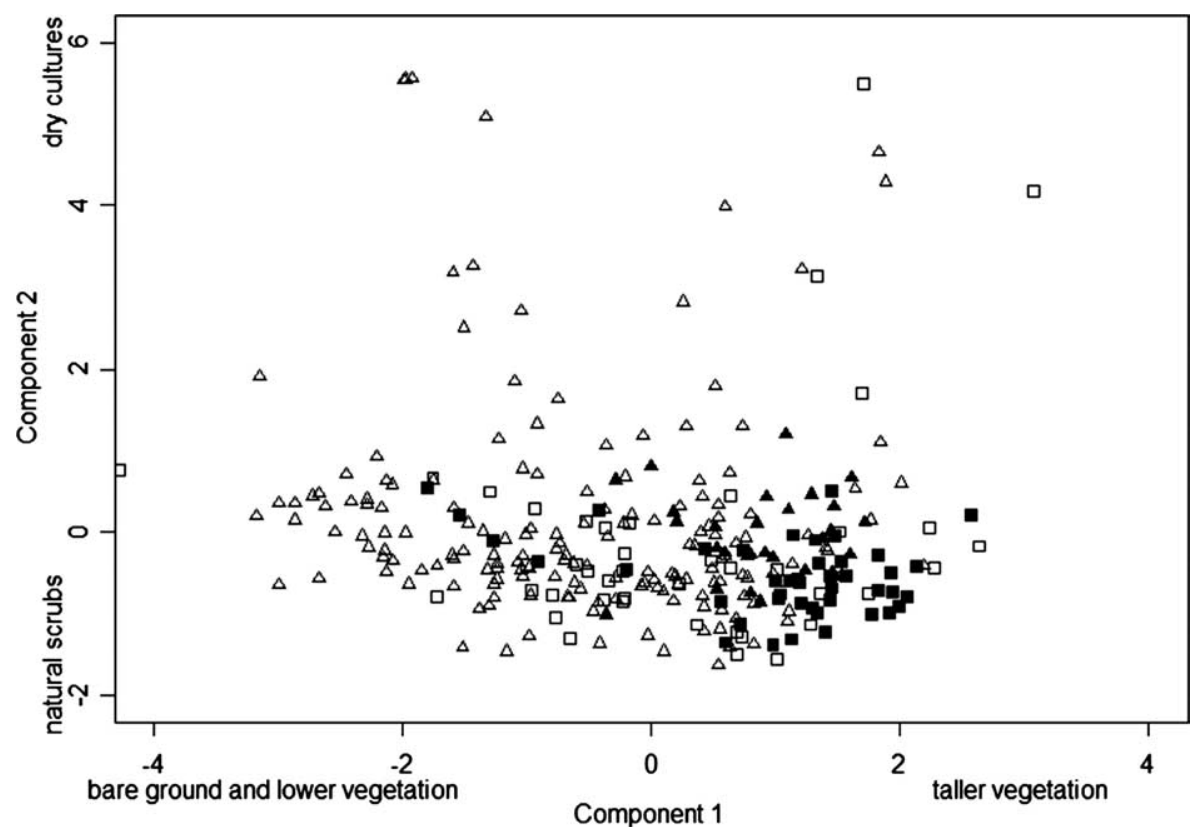

Fig. 2a - Plane formed by the first two axes of the principal component analysis of microhabitat variables (filled symbols: lark sites, open symbols: random sites, squares: year 2001, triangles: year 2004).

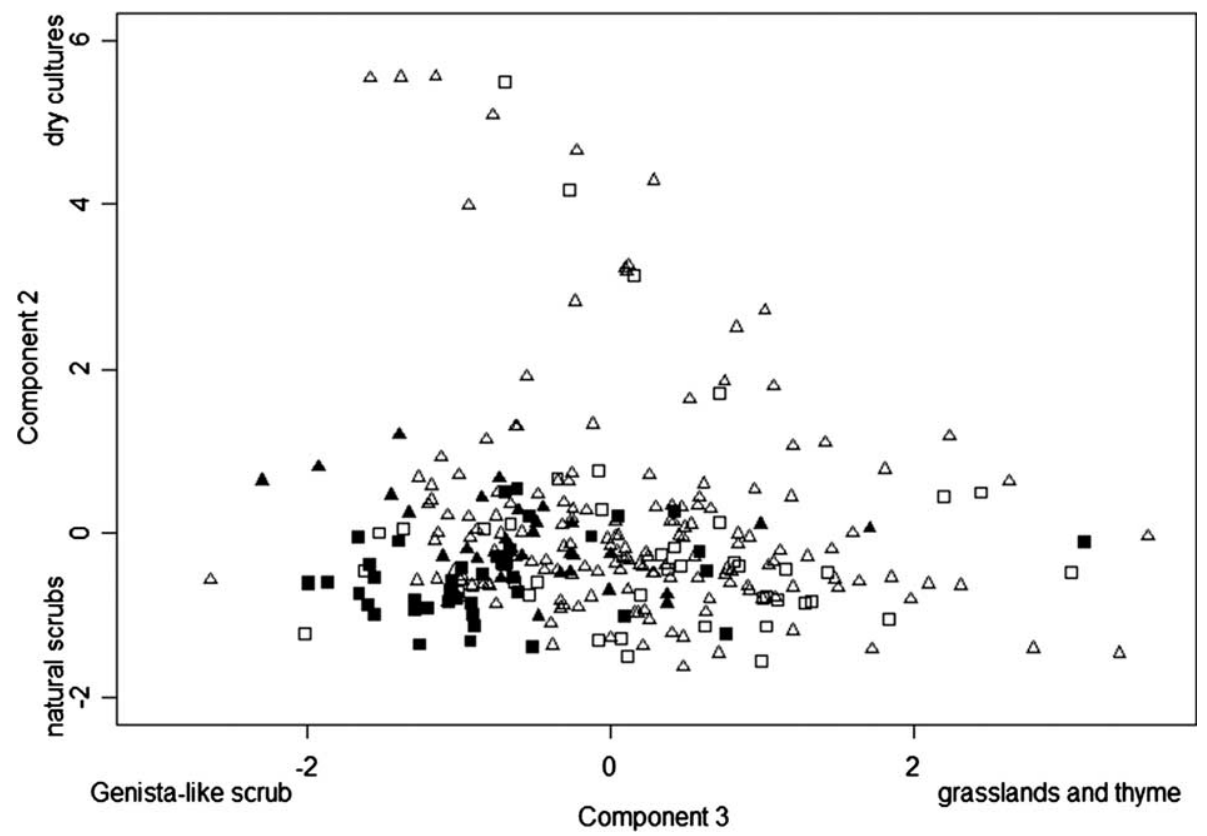

Fig. $2 b$ - Plane formed by the second and third axes of the principal component analysis of microhabitat variables (symbols as above).

\subsection{Assessment of population changes}

The weighted average predictions of models largely overestimated true occurrence frequency in the evaluation sample (year 2004, Fig. 5). Thus we calibrate the map through a logistic regression relating observations and predictions using the binned data (64\% of explained deviance, $p=0.0001)$. The total number of singing birds in the area of study could then be calculated to be 278 (bootstraped 95\% confidence inter- $\mathrm{val}=[191,369])$ of which 261 (C.I. $=[178,346])$ are within the limits of the IBA and 245 (C.I. $=[168,325]$ ) within the SPA (Table 3). These figures can be converted directly into a rough estimate of breeding pairs, if we assume a 1:1 sex ratio and disregard a possible effect of overlapping territories on the predicted probabilities on single 1-ha squares (although steppe passerines may have high male-biased sex-ratios, J.L. Tella, pers. comm.). Similarly, the area exclusive of the IBA (the two northern plains) is predicted to have 33 

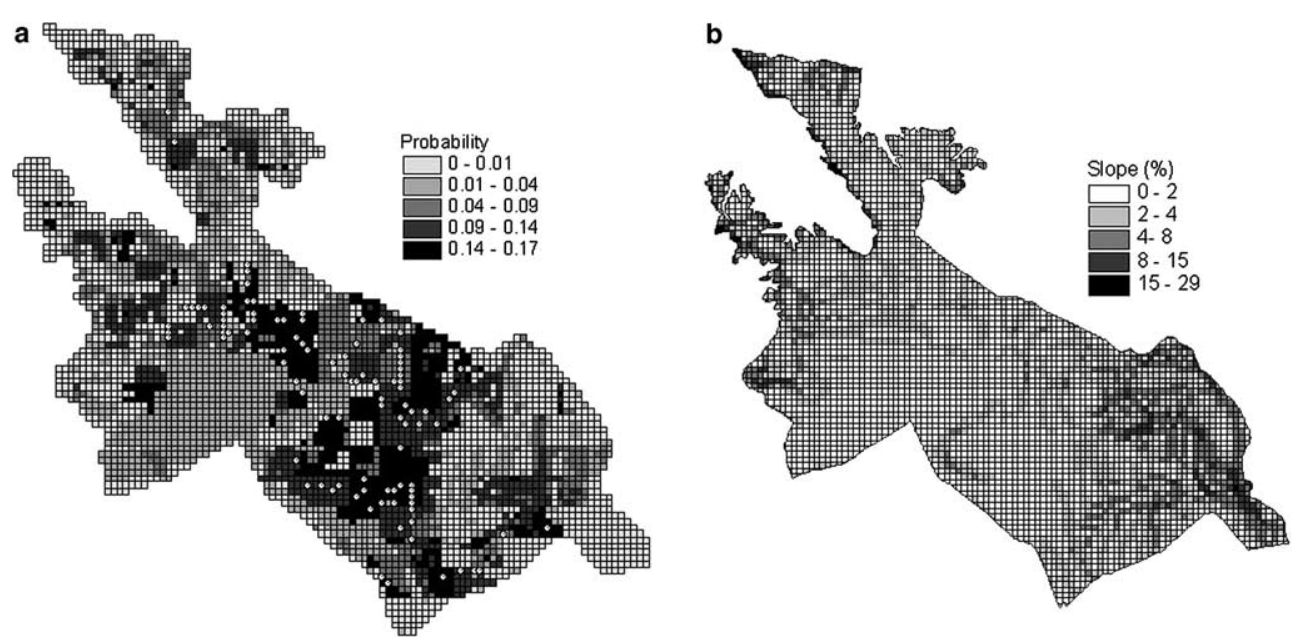

Fig. 3 - (a) Final predictive map of Dupont's lark distribution in the study area. Occurrence probabilities for 1-ha squares are categorized in percentiles and depicted in shades of grey. White circles show squares were larks were actually recorded. (b) Slope map for the study area. Bright colours show flatter terrain.

\begin{tabular}{|c|c|c|c|}
\hline Model & $n$ & CCR & AUC \\
\hline$-3.59(0.45)+1.85(0.51)$ Lavender $-0.59(0.12)$ Tree $-3.86(0.11)$ Rock + 0.03(0.00)Genista & 11 & 0.58 & 0.68 \\
\hline$+1.50(0.11)$ Grass $+0.02(0.00)$ Thyme $-0.24(0.03)$ Slope $-0.45(0.10)$ Crop $+1.53(0.11)$ Rock * Grass & & $(0.02)$ & $(0.01)$ \\
\hline$-4.30(0.47)+1.40(0.51)$ Lavender $-0.71(0.11)$ Tree $-3.88(0.11)$ Rock $+0.03(0.00)$ Genista $+1.26(0.16)$ Grass & 8 & 0.57 & 0.69 \\
\hline$+0.02(0.00)$ Thvme $-0.19(0.03)$ Slope $+1.28(0.16)$ Rock * Grass & & $(0.02)$ & $(0.01)$ \\
\hline$-0.64(0.10)+0.03(0.00)$ Genista $-0.04(0.00)$ Grass $-0.22(0.02)$ Slope & 7 & $\begin{array}{c}0.70 \\
(0.02)\end{array}$ & $\begin{array}{c}0.68 \\
(0.00)\end{array}$ \\
\hline$-1.23(0.05)+0.03(0.00)$ Genista $-0.04(0.00)$ Grass & 7 & $\begin{array}{c}0.69 \\
(0.01)\end{array}$ & $\begin{array}{c}0.67 \\
(0.00)\end{array}$ \\
\hline
\end{tabular}

Shown are the mean and standard error for coefficients of predictive variables, and for the estimates of discriminative ability (CCR: correct classification rate, AUC: area under the curve of a receiver characteristic plot).

$($ C.I. $=[20,47])$ pairs while the area exclusive of the SPA (the southern steep valley) is predicted to have just 18 (C.I. $=[10,28])$ pairs.

A complete conversion of agricultural fields $\left(11.24 \mathrm{~km}^{2}\right)$ to dwarf thyme shrubs and afterwards to small Genista shrubs would result in a maximum gain of $45( \pm 5.6)$ and $229( \pm 15.8)$ pairs respectively, while first stages of afforestation would amount to a loss of $16( \pm 2.9)$ pairs (Table 3$)$. The number of pairs potentially gained by abandonment of agricultural fields in the area exclusive of SPA is small, with a maximum of 21 $( \pm 1.5)$.

\section{Discussion}

We were able to build fairly discriminating models at a spatial resolution that matches the scale needed by managers to address local conservation problems. In addition, the models were developed with a set of descriptive variables easy to record in the field and, in some cases, potentially subjected to future changes. For these reasons we are confident that our results are useful to manage and monitor breeding Dupont's lark population in Layna, and that our modelling approach may be successfully applied elsewhere, at the very least as a qualitative guide for management.

The habitat models' predictions ( $1 \mathrm{ha}$ ) were coherent with Dupont's lark preferences studied at a higher resolution (focal points), one that describes the actual habitat use of birds. In both study scales habitat preferences of Dupont's larks in Layna agree with those found in other areas (Garza and Suárez, 1990; Aragüés, 1992). However, at microhabitat scale these preferences do not differ widely from the available vegetation structure, the differences pointing to an avoidance of crops and to a selection of natural vegetation with greater cover of small shrubs and flatter terrain. We should stress that Dupont's lark habitat preferences for flat terrain has been loosely cited in several previous studies (e.g., Suárez et al., 1982; Aragüés, 1983), but this is the first work to quantitatively measure the effect of ruggedness on the species' occurrence. Our results show that Dupont's lark in Layna plateau avoid areas with slopes steeper than 5.1\% (at 1-ha spatial resolution), which may reduce the effective size of a proposed reserve for the species (it is indeed the case of our study area). The microhabitat preferences translate into a majority of models at 1-ha resolution including Genista cover as an 
model-154

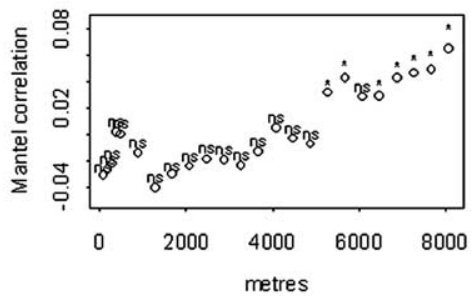

model-64

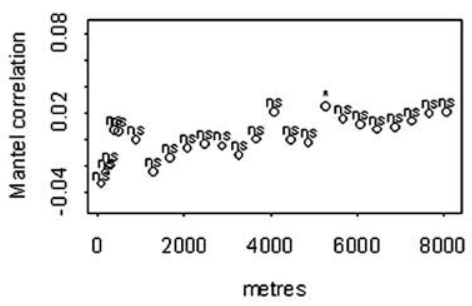

model-98

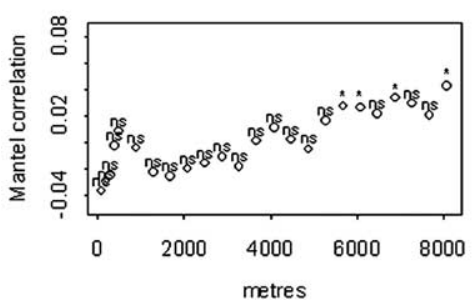

model-1

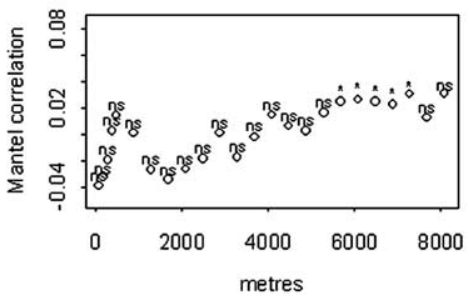

model-127

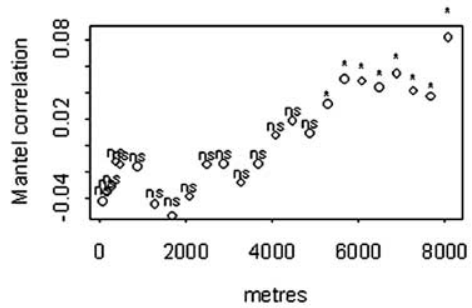

model-34

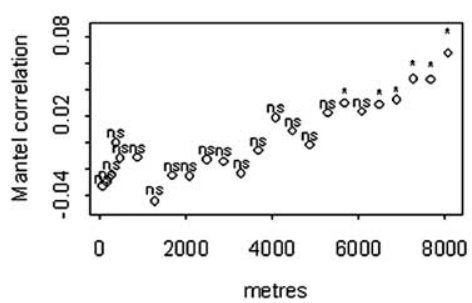

model-81

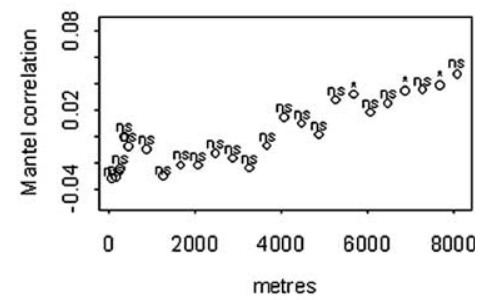

model-104

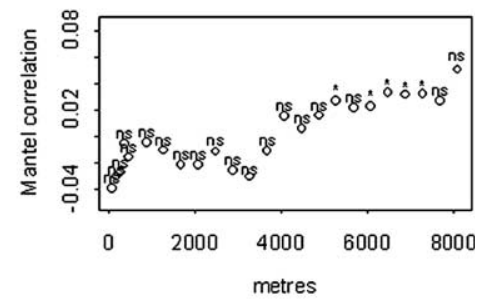

summary

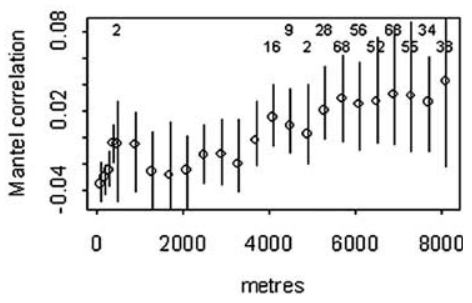

Fig. 4 - Mantel correlograms for the residuals of eight randomly selected resampling models. Circles show the Mantel correlation coefficient per each distance lag among 1-ha squares (asterisks show significant correlations at the Bonferroni-corrected $a=0.05 / 24 ; n s=$ non-significant). The lower-right plot is the summary for the 200 resampling models, with lines showing the range of Mantel correlation coefficients and numbers the percentage of significant results (note that we expect $5 \%$ of the results in each lag to be spuriously significant).

explanatory variable, and the predictive map of Dupont's lark distribution reflects this. The only partial disagreement between our results at different scales is the 1-ha squares categorized as crops having a low, rather than null, predicted probability of Dupont's lark occurrence in the models and thus in the final distribution map. This is because 1-ha squares devoted to cropland frequently have a varying amount of untilled terrain rendering marginal probabilities of species' presence. Similarly, the presence of scattered young trees (saplings) or recent afforestations (seedlings) in the 1-ha squares reduced but did not totally eliminate the presence of Dupont's larks, though we may confidently assume that a higher tree cover than we recorded in our samples would be incompatible with the species.

However, the predictions of our habitat models have to be calibrated before using them as a tool for conservation planning and reserve management, which is a common situation in predictive distribution modelling exercises (Merrill et al., 1999; Palma et al., 1999; Whittingham et al., 2003). In our study, model predictions systematically overestimated true occurrence probabilities. This is mainly a consequence of having equilibrated presences and absences in the building set to avoid well-known biases of logistic regression analyses with unbalanced data (Cramer, 1999; Buchan and Padilla, 2000). As other presences/absences ratios did not substantially improve the predictive power of the model, we stuck with the original analytical design. Additionally, the spatial resolution of our sampling units may be somewhat smaller than territory size of Dupont's lark in Layna plateau (this is up to 4 ha in a nearby site, but with lower densities, see Garza et al., 2003), which may contribute to the overestimation of probabilities (our sampling grid implies that a single 1-ha square may suffice for a pair of larks). Similarly, the spatial analysis similarly suggests that larks may cluster in patches as large as $400 \times 400 \mathrm{~m}$ (16 ha). Nevertheless, the predicted species abundance agreed with previous estimates obtained by Finnish transects in, roughly, the same area of study (500 pairs in $45 \mathrm{~km}^{2}$ in Garza and Suárez, 1992; between 250 and 500 pairs in $21 \mathrm{~km}^{2}$ according to Viada, 1998; Viada, 2000), after taking into account the overestimation of true densities that Finnish transects seem to cause for this species (Garza et al., 2003). It should also be noted that predictive power, as measured by AUC, is under the 0.7 threshold normally given in the modelling literature to consider the model to be satisfactory. However, we make here an external validation to confront the model to a complete new set of observations taken 


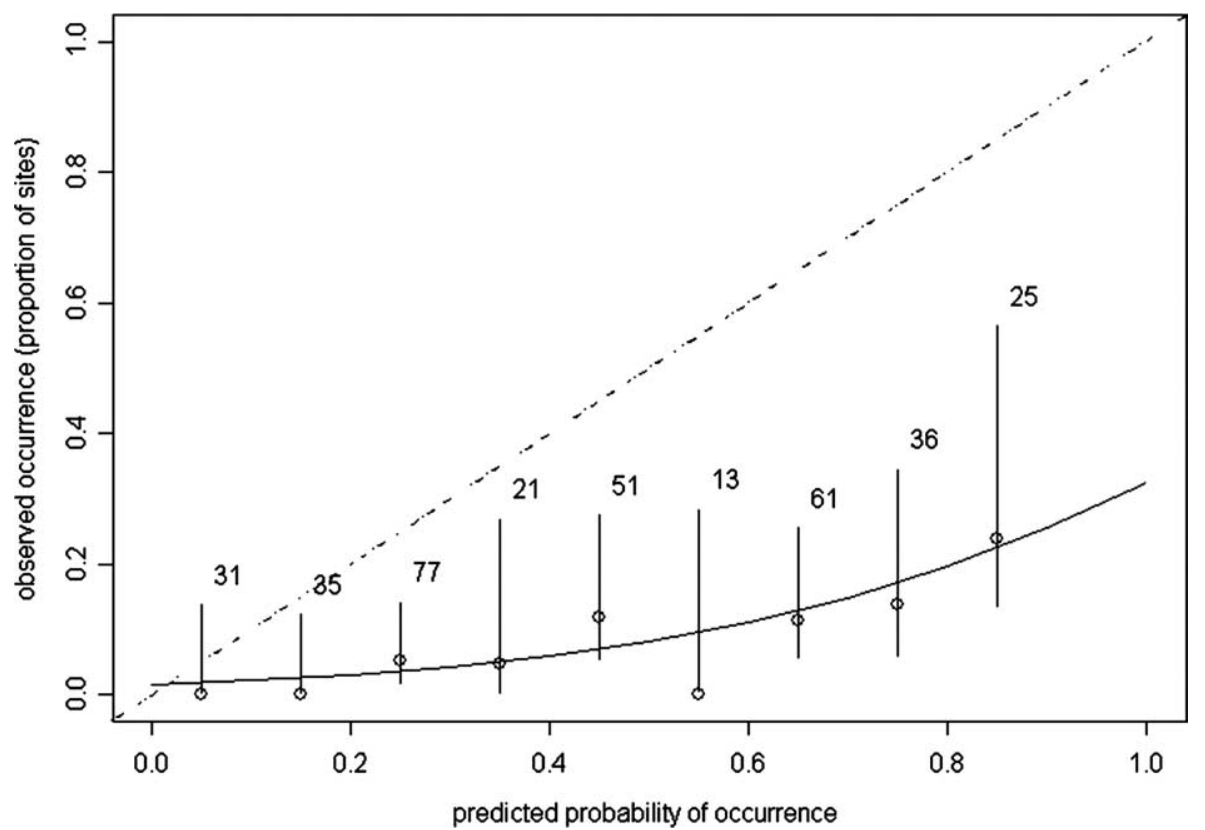

Fig. 5 - Calibration graph. The proportion of evaluation 1-ha squares with presence of Dupont's lark, within each of ten predicted probability classes, is plotted against the observed occurrence in each class (circles). The solid line is the logistic regression between observations and predictions with binned data (weighted averages of 200 habitat models) that we used to correct the predictions of occurrence. This relationship would follow the dashed line in a perfectly calibrated model. Bars show binomial standard errors and figures are sample sizes within each class.

\section{Table 3 - Assessment of population changes following three scenarios of land transformation}

\begin{tabular}{llll} 
Scenarios & IBA (3775 ha) & SPA (3170 ha) & IBA + SPA (4219 ha) \\
\hline Current & 261 & 245 & 278 \\
& $(178,346)$ & $(168,325)$ & $(191,369)$ \\
1 (to dwarf shrubs) & +41 & +38 & +45 \\
& $(39,46)$ & $(33,42)$ & $(39,50)$ \\
2 (to small shrubs) & +208 & +192 & +229 \\
& $(193,222)$ & $(178,205)$ & $(213,244)$ \\
3 (afforested) & -15 & -14 & -16 \\
& $(-17,-12)$ & $(-11,-16)$ & $(-13,-19)$
\end{tabular}

First row (current) shows the predictions for the present land cover, while rows for scenarios 1-3 show respectively predictions for agricultural fields being converted into dwarf thyme shrubs, small Genista shrubs and afforested areas. Data are averaged predictions (and $95 \%$ confidence intervals) for the difference between current numbers and those corresponding to the forecasted scenarios (to be interpreted as increment in number of pairs) for 200 habitat models weighted by AIC. The study areas (IBA and SPA) do not completely overlap (see Fig. 1).

some years later than the original data, which is a very stringent procedure rarely tried in previous modelling exercises. What is more, the differences in the development of the vegetation between sampling years may hinder the predictions, but if we are to use habitat modelling on the Mediterranean Region we should face the fact that interannual changes are the norm and not the exception in this area (see, for example, Blondel and Aronson, 1999, pp. 21-24).

Our analyses allow us to compare the effectiveness of alternative reserve designs in terms of the number of both current and potential pairs estimated to breed within their limits. In our case study, the limits of the Special Protected Area for birds set by the regional environmental administration followed closely those of the Important Bird Area, except for two potentially conflictive sectors that were kept out of the reserve and substituted for an adjacent area. The SPA final size is just $16 \%$ smaller than that of the IBA and both have sparse shrub vegetation, so it is easy to assume that the number of protected pairs under the two alternative limits should not differ greatly. However, the sector exclusive to the SPA has fewer small shrub open formations favoured by Dupont's lark and, worst, it is mostly composed of hilly and rugged terrain in total opposition with Dupont's lark habitat preferences. However, the models fail to discriminate sharply between the two zones probably both because the slope has much less variability than the rest of predictors, and because the flat northernmost areas of the IBA are covered by sub-optimal habitat (grasslands, which, however, could be transformed into shrubland). UE members are recommended to take national IBA inventories as the basis for declaring SPAs, and a 
judgement of the European Court of Justice mandates that at least $50 \%$ of the surface covered by IBAs should be declared SPAs (case C-3/96 lost by the Netherlands, 19/05/1998). However, matching the amount of total protected area - even within seemingly homogeneous vegetation formations - does not necessarily equal to match the level of prescribed protection for a species, as our study has shown (see Miller, 2000). Thus, we urge managers to quantitatively assess the habitat needs of species to appropriately set the limits of protected areas, and suggest that the methods we present in this work can adequately serve this purpose (see Araújo et al. (2002) for a further benefit of habitat models: their predictions correlate with local persistence).

Our case study area belongs to Castilla y León province, a region under Structural Funds objective 1 (Council Regulation (EC) No. 1260/1999), and it also qualifies to be considered as a less-favoured area for agriculture, therefore it is prioritised to receiving European subsidies. According to Dupont's lark habitat preferences, the CAP regulations and accompanying measures that may be implemented in the area of study would have a varying effect on the breeding population of the species. Measures within CAP Pillar I and agri-environmental schemes focusing on agricultural extensification would likely be beneficial for the species (Donald et al., 2001). Such is the case of set-aside (abandonment of cereal fields) and measures enforcing fallow land (temporal non-tillage), which would promote a land change to natural grasslands first and then open small shrubs, the preferred vegetation for Dupont's lark. A maximum of $80 \%$ increase on breeding population size could then be envisaged. Similarly, a low grazing pressure would likely keep this vegetation structure and thus favour the species occurrence. On the contrary, afforestation is obviously detrimental for a shrub-steppe species, though the effect may be delayed until the seedlings eventually reach a shape and height different from that of the surrounding shrub vegetation (we have seen a male occupying a recently afforested area, covered by seedlings $20 \mathrm{~cm}$ in height and extensive bare ground). In addition, afforestation works are normally performed by ploughing the soil with heavy machinery, which creates deep furrows and increases the unevenness of the terrain to a level likely unbearable for the species. Similarly, a less probable agricultural intensification promoted by the normal CAP support to productivity would reduce the effective habitat area for Dupont's lark as it has done for other steppe species (see, for example, Inchausti and Bretagnolle, 2005).

Our species and area of study exemplifies a common conflict among the variety of measures implemented to attain agricultural and conservation goals in the European Union (Donald et al., 2001). On the one hand, the medium-term objective of halting the loss of biodiversity by 2010 is expected to be attained with several means, particularly with the development of Natura 2000 net of protected areas (European-Communities, 2001). Under the provisions of Habitat Directive, the SPAs such as the area of study will be part of this net, whose financial allocation is yet to be determined. On the other hand, the Agenda 2000 CAP reform aims at shaping a modern European agricultural model, one that is stated to balance the development of rural areas (Zervoudaki, 1999). However, the majority of the CAP expenditure for the period 2000-2006 (297,740 millions Euro) will still be employed in market measures and only a roughly $10 \%$ in rural development, that includes the CAP accompanying measures (Zervoudaki, 1999). Therefore most of the CAP expenditure will be made without a main environmental concern and could negatively affect biodiversity (Krebs et al., 1999). To avoid this conflict, the EU is on its way to strengthen the second pillar of the CAP, and to "green" the first pillar by developing mechanisms of eco-conditionality (i.e., receptors qualify for financial aid only if they meet a set of environmentally friendly farming practices) and decoupling payments from productivity (i.e., rewarding farmers for making environmental improvements to their land, see Donald et al., 2002). Nevertheless, the actual implementation of these mechanisms may confront immediate conservation needs (as we have seen with afforestation) and their potential benefits depend on the territorial context (Horst and Gimona, 2005; Ursua et al., 2005) . Therefore management prescriptions within subsidy schemes (e.g., fallow regime and timing, set-aside and extensification policies, etc.) should strictly respect conservation objectives, particularly the urgent protection needs of the Natura 2000 net of sites. An advisable emphasis on monitoring and evaluation studies of changing agricultural practises on biodiversity would tell us whether agri-environmental schemes are hitting their marks.

\section{Acknowledgements}

Carlos Hernáez helped with the field work, Inmaculada de la Concha, Juan Carlos Illera and José Luis Tella made invaluable comments to previous versions of the manuscript, while Julieta Valls helped with GIS analyses and Matthew Kleban and Raúl Rabadán with the English. We also thank Francisco Suárez and José Luis Tella for productive discussion and for his continuous support to Spanish shrub-steppes conservation. Finally, we thank the Centro Nacional de Información Geográfica for expediting the acquisition of DTM data. This work was possible thanks to funding from the government of Castilla y León and the Gestor de Infraestructuras Ferroviarias.

\section{R E F E R E N C E S}

Aragüés, A., 1983. Dupont's Lark in the Spanish steppes. British Birds 76, 57-62.

Aragüés, A., 1992. La alondra de Dupont (Chersophilus duponti) en la región aragonesa. Facultad de Veterinaria, Universidad de Zaragoza, Zaragoza.

Araújo, M.B., Williams, P.H., 2000. Selecting areas for species persistence using occurrence data. Biological Conservation 96, 331-345.

Araújo, M.B., Williams, P.H., Fuller, R.J., 2002. Dynamics of extinction and the selection of nature reserves. Philosophical Transactions Royal Society of London, Series B 269, 1971-1980.

Austin, M., 2002. Spatial prediction of species distribution: an interface between ecological theory and statistical modelling. Ecological Modelling 157, 101-118.

Bailey, S.-A., Haines-Young, R.H., Watkins, C., 2002. Species presence in fragmented landscapes: modelling of species 
requirements at the national level. Biological Conservation 108, 307-316.

Berry, P.M., Dawson, T.P., Harrison, P.A., Pearson, R.G., 2002. Modelling potential impacts of climate change on the bioclimatic envelope of species in Britain and Ireland. Global Ecology and Biogeography 11, 453-462.

Bibby, C.J., Burgess, N.D., Hill, D.A., Mustoe, S.H., 2000. Bird Census Techniques. Academic Press, London.

Blondel, J., Aronson, J., 1999. Biology and Wildlife of the Mediterranean Region. Oxford University Press, New York.

Brotons, L., Mañosa, S., Estrada, J., 2004. Modelling the effects of irrigation schemes on the distribution of steppe birds in Mediterranean farmland. Biodiversity and Conservation 13, 1039-1058.

Buchan, L.A.J., Padilla, D.K., 2000. Predicting the likelihood of the water milfoil presence in lakes, a macrophyte monitoring tool. Ecological Applications 10, 1442-1455.

Bustamante, J., Seoane, J., 2004. Predicting the distribution of four species of raptors (Accipitridae) in southern Spain: statistical models work better than existing maps. Journal of Biogeography 31, 295-306.

Caughley, G., Gunn, A., 1996. Conservation Biology in Theory and Practice. Blackwell Science, Oxford.

Conroy, M.J., Noon, B.R., 1996. Mapping of species richness for conservation of biological diversity: conceptual and methodological issues. Ecological Applications 6, 763-773.

Cramer, J.S., 1999. Predictive performance of the binary logit model in unbalanced samples. Journal of the Royal Statistical Society, Series D 48.

Cramp, S. (Ed.), 1988. Handbook of the Birds of Europe, the Middle East and North Africa: The Birds of the Western Paleartic. Oxford University Press, New York.

De Juana, E., 2004. Cambios en el estado de conservación de las aves en España, años 1954 a 2004. Ardeola 51, 19-50.

Donald, P.F., Green, R.E., Heath, M.F., 2001. Agricultural intensification and the collapse of Europe's farmland bird populations. Proceedings of the Royal Society of London, Series B: Biological Sciences 268, 25-29.

Donald, P.F., Pisano, G., Rayment, M.D., Pain, D.J., 2002. The Common Agricultural Policy, EU enlargement and the conservation of Europe's farmland birds. Agriculture, Ecosystems and the Environment 89, 167-182.

Eastman, J.R., 1999. IDRISI32. Clark Labs, Clark University, Worcester.

Ertsen, A.C.D., Bio, A.M.F., Bleuten, W., Wassen, M.J., 1998. Comparison of the performance of species response models in several landscape units in the province of Noord-Holland, The Netherlands. Ecological Modelling 109, 213-223.

European-Communities, 2001. Environment 2010: our future, our choice. Office for official publication of the European Communities, Luxembourg.

European-Communities, 2003. Rural development in the European Union. European Comission, Agriculture and Rural Development, Luxembourg.

Franco, A.M.A., Sutherland, W.J., 2004. Modelling the foraging habitat selection of lesser kestrels: conservation implications of European Agricultural Policies. Biological Conservation 120, 63-74.

Garza, V., Suárez, F., 1990. Distribución, población y selección de hábitat de la alondra de Dupont (Chersophilus duponti) en la Península Ibérica. Ardeola 37, 3-12.

Garza, V., Suárez, F., 1992. Estudio para la inclusión de zonas esteparias de la Comunidad de Castilla y León en la red de espacios naturales. Sociedad Española de Ornitología, Madrid.

Garza, V., Suárez, F., Tella, J.L., 2005. Alondra Ricotí Chersophilus duponti. In: Madroño, A., González, C., Atienza, J.C. (Eds.), Libro Rojo de las aves de España. Dirección General de Conservación de la Naturaleza-SEO/Bird Life, Madrid, pp. 309-312.
Garza, V., Traba, J., Suárez, F., 2003. Is the European population of Dupont's Lark Chersopilus duponti adequately estimated. Bird Study 50, 309-311.

Grand, J., Cushman, S.A., 2003. A multi-scale analysis of species-environment relationships: breeding birds in a pitch pine-scrub oak (Pinus rigida-Quercus ilicifolia) community. Biological Conservation 112, 307-317.

Guisan, A., Zimmermann, N.E., 2000. Predictive habitat distribution models in ecology. Ecological Modelling 135, 147-186.

Horst, D.V.D., Gimona, A., 2005. Where new farm woodlands support biodiversity action plans: a spatial multi-criteria analysis. Biological Conservation 123, 421.

Inchausti, P., Bretagnolle, V., 2005. Predicting short-term extinction risk for the declining Little Bustard (Tetrax tetrax) in intensive agricultural habitats. Biological Conservation 122, 375-384.

Krebs, J.R., Wilson, J.D., Bradbury, R.B., Siriwardena, G.M., 1999. The second silent spring? Nature 400, 611-612.

Larsen, D.L., Bock, C.E., 1986. Determining avian habitat preference by bird-centered vegetation sampling. In: Verner, J., Morrison, M.L., Ralph, C.J. (Eds.), Wildlife 2000. Modeling habitat relationships of terrestrial vertebrates. The University of Wisconsin Press, Madison, pp. 37-43.

Legendre, P., 1993. Spatial autocorrelation: trouble or new paradigm? Ecology 74, 1659-1673.

Legendre, P., Fortin, M.-J., 1989. Spatial pattern and ecological analysis. Vegetatio 80, 107-138.

MacNally, R., 2000. Regression and model-building in conservation biology, biogeography and ecology: the distinction between - and reconciliation of - 'predictive' and 'explanatory' models. Biodiversity and Conservation 9, 655-671.

Manel, S., Williams, H.C., Ormerod, S.J., 2001. Evaluating presence-absence models in ecology: the need to account for prevalence. Journal of Applied Ecology 38, 921-931.

Margules, C.R., Austin, M.P., 1994. Biological models for monitoring species decline: the construction and use of data bases. Philosophical Transactions of the Royal Society of London, Series B: Biological Sciences 344, 69-75.

Martí, R., Del Moral, J.C. (Eds.), 2003. Atlas de las aves reproductoras de España. Ministerio de Medio Ambiente - SEO/BirdLife, Madrid.

Martínez, J.A., Serrano, D., Zuberogoitia, I., 2003. Predictive models of habitat preferences for the Eurasian eagle owl Bubo bubo: a multiscale approach. Ecography 26, 21-28.

MathSoft, I., 1999. S-Plus 2000 Professional Release 2. MathSoft, Inc., Seattle, WA.

Mazerolle, M.J., Villard, M.A., 1999. Patch characteristics and landscape context as predictors of species presence and abundance: a review. Ecoscience 6, 117-124.

Merrill, T., Mattson, D.J., Wright, R.G., Quigley, H.B., 1999. Defining landscape suitable for restoration of grizzly bears Ursus arctos in Idaho. Biological Conservation 87, 231-248.

Miller, C.J., 2000. Vegetation and habitat are not synonyms. Ecological Management \& Restoration 1, 102-104.

Morillo, C., Gómez-Campo, C., 2000. Conservation in Spain, 1980-2000. Biological Conservation 95, 165-174.

Orrock, J.L., Pagels, J.F., McShea, W.J., Harper, E.K., 2000. Predicting presence and abundance of a small mammal species: the effect of scale and resolution. Ecological Applications 10, 1356-1366.

Palma, L., Beja, P., Rodrigues, M., 1999. The use of sighting data to analyze Iberian lynx habitat and distribution. Journal of Applied Ecology 36, 812-824.

Pearce, J., Ferrier, S., 2000. Evaluating the predictive performance of habitat models developed using logistic regression. Ecological Modelling 133, 225-245.

Rice, W.R., 1989. Analyzing tables of statistical tests. Evolution 43, 223-225. 
Riitters, K.H., O’Neill, R.V., Jones, K.B., 1997. Assessing habitat suitability at multiple scales: a landscape-level approach. Biological Conservation 81, 191-202.

Seoane, J., Viñuela, J., Díaz-Delgado, R., Bustamante, J., 2003. The effects of land use and climate on red kite distribution in the Iberian peninsula. Biological Conservation 111, 401-414.

Suárez, F., Naveso, M.A., De Juana, E., 1997. Farming in the drylands of Spain: birds of the pseudosteppes. In: Pain, D.J., Pienkowski, M. (Eds.), Farming and Birds in Europe. Academic Press, London, pp. 297-330.

Suárez, F., Santos, T., Tellería, J.L., 1982. The status of Dupont's Lark Chersophilus duponti in the Iberian Peninsula. Le Gerfaut 72, 231-235.

Tella, J.L., Vögeli, M., Serrano, D., Carrete, M., 2005. Current status of the threatened Dupont's lark in Spain: overestimation, decline, and extinction of local populations. Oryx 39, 90-94.

Thuiller, W., 2003. BIOMOD - optimizing predictions of species distributions and projecting potential future shifts under global change. Global Change Biology 9, 1353-1362.

Tucker, G.M., Dixon, J., 1997. Agricultural and grassland habitats. In: Tucker, G.M., Evans, M.I. (Eds.), Habitats for Birds in Europe:
A Conservation Strategy for the Wider Environment. BirdLife International, Cambridge, UK, pp. 267-325.

Tucker, G.M., Evans, M.I. (Eds.), 1997. Habitats for Birds in Europe: A Conservation Strategy for the Wider Environment. BirdLife International, Cambridge, UK.

Ursua, E., Serrano, D., Tella, J.L., 2005. Does land irrigation actually reduce foraging habitat for breeding lesser kestrels? The role of crop types. Biological Conservation 122, 643-648.

Venables, W.N., Ripley, B.D., 1999. Modern Applied Statistics with S-PLUS. Springer-Verlag, New York.

Viada, C., 1998. Áreas importantes para las aves en España. SEO/BirdLife, Madrid.

Viada, C., 2000. Spain (including the Canary Islands). In: Heath, M.F., Evans, M.I. (Eds.), Important Bird Areas in Europe: Priority Sites for Conservation. BirdLife International, Cambridge, UK, pp. 515-649.

Whittingham, M.J., Wilson, J.D., Donald, P.F., 2003. Do habitat association models have any generality? Predicting skylark Alauda arvensis abundance in different regions of southern England. Ecography 26, 521-531.

Zervoudaki, S., 1999. CAP reform: rural development. Comisión Europea, Dirección General de Agricultura, Bruselas. 